\title{
Modeling and optimal control of a wheel loader in the lift-transport section of the short loading cycle
}

Vaheed Nezhadali, Lars Eriksson and Anders Fröberg

\author{
Linköping University Post Print
}

\section{Tweet}

N.B.: When citing this work, cite the original article.

Original Publication:

Vaheed Nezhadali, Lars Eriksson and Anders Fröberg, Modeling and optimal control of a wheel loader in the lift-transport section of the short loading cycle, 2013, Elsevier IFAC Publications / IFAC Proceedings series, (46), 21, 195-200.

http://dx.doi.org/10.3182/20130904-4-JP-2042.00083

Copyright: Elsevier

http://www.elsevier.com/

Postprint available at: Linköping University Electronic Press

http://urn.kb.se/resolve?urn=urn:nbn:se:liu:diva-128706 


\title{
Modeling and optimal control of a wheel loader in the lift-transport section of the short loading cycle
}

\author{
V. Nezhadali * L. Eriksson* A. Fröberg ** \\ * Electrical Engineering Department, Linköping University, SE-581 83 \\ Linköping, Sweden (e-mail: \{vaheed.nezhadali,larer\}@liu.se) \\ ** Volvo Construction Equipment, SE-63185 Eskiltuna, Sweden \\ (e-mail: anders.froberg@volvo.com)
}

\begin{abstract}
Optimal control of a wheel loader operating in the short loading cycle is studied in order to investigate the potentials for fuel consumption reduction while maintaining acceptable production rates. The wheel loader is modeled as a system with five states and three control inputs including torque converter nonlinearities. The torque converter is modeled with no lockup enabling power transmission in both directions. The geometry of the wheel loader boom and the demanded force in the lift cylinders during lifting are used to ensure that the in-cylinder pressure remains below component's limits. The lift-transport section of the short loading cycle is divided into four phases due to discontinuities in the gearbox ratios and fuel consumption is calculated in each phase. Time optimal and fuel optimal transients of the system and the power consumption in each and every component is presented showing the dominance of the torque converter losses compared to the other components especially in the time optimal solutions. It is shown that introducing path constraints on the maximum lifting speed of the bucket due to limitations in hydraulic pumping speed moves the diesel engine operation towards higher speeds in order to maintain the lifting speed. Trade-off between fuel optimal and time optimal transients is calculated which is found to be in agreement with the results of experimental studies.
\end{abstract}

Keywords: Multi phase optimal control, wheel loader model, short loading cycle, torque converter

\section{INTRODUCTION}

Wheel loaders are widely used at construction sites in order to transfer various types of loads. These machines can be considered as an integrated system of hydraulic, mechanic and electronic subsystems. Wheel loader operation includes load lifting and transport tasks where the implemented strategy for the control of the different subsystems affects the fuel consumption and production rates of the main system. Optimal control of the wheel loader operation is informative since it highlights the potentials for the fuel consumption reduction and shortening of the operational time. The results provide valuable knowledge in the design of autonomous wheel loader control systems and strategies, Cobo et al. (1998). According to Frank et al. (2012) these control systems enable the machine operator to perform the tasks in a more fuel efficient way while maintaining acceptable production rates. The short loading cycle, depicted in Fig. 1 is a frequent wheel loader application where the load lifting and transport calls for power in hydraulic subsystem and the driveline. According to Filla (2011), the cycle can be divided into two main sections with the highest fuel consumption rates namely bucket filling and lift-transport. Fuel consumption in the bucket filling section depends on the geometry of the bucket and also the load (for example gravel, timber, rock); whereas, the fuel consumption in the lift-transport section is comparable for various short loading cycles as

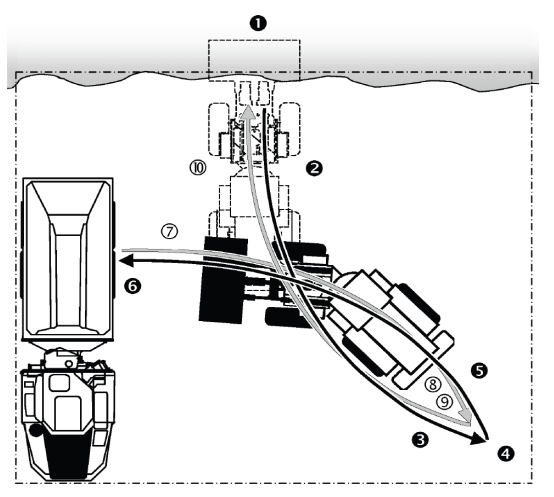

Fig. 1. Numbered sequence of actions in a short loading cycle, picture from Filla (2011).

the vehicle should always travel towards a load receiver at a certain distance while the load is lifted to a specific height. This study is focused on the optimal control of the wheel loader operation in the lift-transport section of the short loading cycle while the following are addressed:

- Development of a model for the wheel loader as a system with five states and three control inputs.

- Representing the lift-transport section of short loading cycle as a four phase optimal control problem and solving it for minimum fuel consumption and minimum cycle time. 


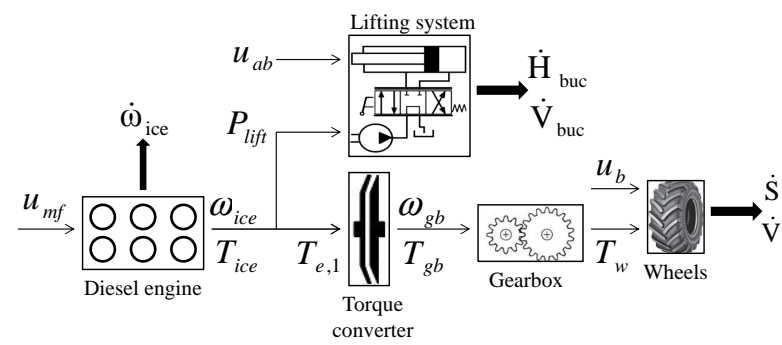

Fig. 2. Wheel loader system model showing the interdependence between system components.

- Investigating the power distribution in the system and calculating the component losses over the cycle.

- Studying the effects of component limitations and torque converter stiffness on the system transients.

- Illustrating the trade-off between time optimal and fuel optimal controls as a Pareto front.

The transportation distance is assumed to be known, the bucket load is set to the maximum capacity of the machine, and the components are modeled based on the properties in the product brochure (Volvo (2012)) where PROPT (TOMLAB (2012)) is the optimal control problem solver used to solve the multi-phase optimal control problem.

\section{WHEEL LOADER SYSTEM MODEL}

The wheel loader is modeled by five components namely diesel engine, lifting system, torque converter (TC), gearbox and wheels. Fig. 2 shows an overview of the system components and the interdependence between the components. Control inputs to the system are fuel injection per engine cycle, $U_{m f}$, bucket acceleration, $U_{a b}$, and braking torque, $U_{b}$. The system states are engine speed, $\omega_{i c e}$, vehicle position, $S$, vehicle speed, $V$, bucket height, $H_{b u c}$, and bucket lift speed $V_{b u c}$ which are determined by solving the following differential equations:

$$
\begin{aligned}
\frac{d \omega_{i c e}}{d t} & =\frac{1}{J_{i c e}}\left(T_{i c e}\left(U_{m f}, \omega_{i c e}\right)-\frac{P_{\text {load }}\left(V_{b u c}, V\right)}{\omega_{i c e}}\right) \\
\frac{d S}{d t} & =V \\
\frac{d V}{d t} & =\frac{\operatorname{sign}(V)\left(F_{\text {trac }}\left(U_{b}, \omega_{i c e}\right)-F_{\text {roll }}\right)}{M_{t o t}} \\
\frac{d H_{b u c}}{d t} & =V_{b u c} \\
\frac{d V_{b u c}}{d t} & =U_{a b}
\end{aligned}
$$

where $\gamma$ is the gear ratio of the gearbox and $P_{\text {load }}$ is the sum of powers required for lifting, $P_{l i f t}$, and traction, $P_{\text {trac }}$, which will be calculated in the sequel.

\subsection{Diesel engine}

A simplified version of the nonlinear mean value engine model in Eriksson (2007) is utilized for a 6 cylinder 12 liter engine $\left(n_{c y l}=6, V_{d}=12 \mathrm{~L}\right)$ where $\omega_{i c e}$, determined by (1), is the state variable and $U_{m f}$ is the control input. Engine torque, $T_{i c e}$, is modeled as the subtraction of friction torque, $T_{\text {fric }}$, from indicated gross torque, $T_{i g}$ :

$$
\begin{aligned}
& T_{i c e}\left(U_{m f}, \omega_{i c e}\right)=T_{i g}\left(U_{m f}\right)-T_{f r i c}\left(\omega_{i c e}\right) \\
& T_{i g}\left(U_{m f}\right)=\frac{\eta_{i g} q_{h v} n_{c y l} U_{m f} 10^{-6}}{4 \pi} \\
& T_{f r i c}\left(\omega_{i c e}\right)=\frac{V_{d} 10^{5}}{4 \pi}\left(c_{f r 1} \omega_{i c e}^{2}+c_{f r 2} \omega_{i c e}+c_{f r 3}\right) \\
& \dot{m}_{f}\left(U_{m f}, \omega_{i c e}\right)=\frac{10^{-6}}{4 \pi} U_{m f} \omega_{i c e} n_{c y l}
\end{aligned}
$$

the tuning parameters are $\eta_{i g}$ and $c_{f r 1,2,3}$ and $q_{h v}$ is the heating value of the fuel. The limits on the engine torque $T_{i c e, l i m}\left(\omega_{i c e}\right)$ are modeled by three lines as depicted in Fig. 7 according to the product brochure.

\subsection{Lifting system}

The power required for lifting, $P_{\text {lift }}$, is calculated as follows. $U_{a b}$ is the control input to the system while $H_{b u c}$ and $V_{b u c}$ are the states determined by (4) and (5).

$$
\begin{aligned}
& F_{\text {load }}=M_{\text {load }}\left(g+U_{a b}\right) \\
& P_{\text {lift }, \text { net }}=F_{\text {load }} V_{\text {buc }} \quad, \quad P_{\text {lift }}=\frac{P_{\text {lift }, \text { net }}}{\eta_{\text {lift }}}
\end{aligned}
$$

where $g=9.81\left[\mathrm{~m} / \mathrm{s}^{2}\right], M_{b u c}=10$ [ton] is set according to product brochure and $\eta_{\text {lift }}=0.9$ is assumed as the hydraulic system's efficiency. Fig. 3 illustrates the positioning of lift cylinder(s) (two parallel cylinders) with respect to the wheel loader boom and body. The vertical displacement of the boom end is a multiplication of the lift piston displacement by a variable factor which is a function of boom angle, $\theta_{2}$. This factor, $k\left(\theta_{2}\right)$, is calculated as follows:

$$
\begin{aligned}
& \theta_{2}=\sin ^{-1}\left(\frac{H_{b u c}-G}{r}\right), \theta_{1}=\tan ^{-1}\left(\frac{r_{1} \cos \left(\theta_{2}\right)-x_{c}}{r_{1} \sin \left(\theta_{2}\right)-y_{c}}\right) \\
& L_{c y l}=\sqrt{\left(r_{1} \cos \left(\theta_{2}\right)-x_{c}\right)^{2}+\left(r_{1} \sin \left(\theta_{2}\right)-y_{c}\right)^{2}} \\
& k\left(\theta_{2}\right)=\frac{\Delta\left(r \sin \left(\theta_{2}\right)\right) / \Delta \theta_{2}}{\Delta L_{c y l} / \Delta \theta_{2}} \quad, \quad r=r_{1}+r_{2}
\end{aligned}
$$

where $\mathrm{G}$ is the height of boom-body joint from the ground level and $r_{1}, r_{2}, x_{c}$ and $y_{c}$ are dimensions illustrated in Fig. 3 based on product brochure. The maximum lifting speed, $V_{\text {lift,max }}$, is achieved when the hydraulic pump operates at its maximum displacement, $D_{\text {pump, max }}$, and delivers the maximum hydraulic flow, $Q_{\text {pump }}$, where the pump speed is equal to $\omega_{i c e}$. Knowing the value of $k\left(\theta_{2}\right)$ from (14), the maximum bucket lifting speed can be calculated as:

$$
\begin{aligned}
& A_{\text {piston }}=\pi\left(r_{\text {piston }}^{2}-r_{\text {rod }}^{2}\right) \\
& Q_{\text {pump }}=\omega_{\text {ice }} \times D_{\text {pump }, \text { max }} \eta_{\text {volumetric }} \\
& v_{\text {pist } \text { max }}=\frac{Q_{\text {pump }} \eta_{\text {cyl }, l}}{A_{\text {piston }}} \\
& V_{\text {lift }, \text { max }}=k\left(\theta_{2}\right) v_{\text {pist }, \text { max }}
\end{aligned}
$$

where $r_{\text {piston }}, r_{\text {rod }}$ and $D_{\text {pump,max }}$ are taken from product brochure and it is assumed that $\eta_{\text {volumetric }}=0.98$ and $\eta_{c y l, l}=0.95$. Forces exerted on the boom are calculated by solving the force equilibrium equations in $x$ and $y$ directions and moment equilibrium around the boom-body joint at $\mathrm{O}$ : 


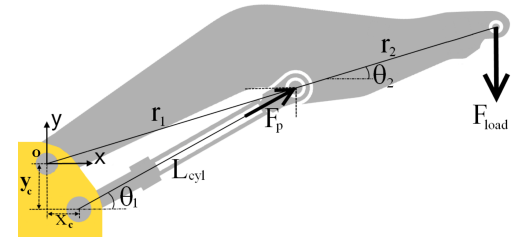

Fig. 3. The geometry of boom and lift cylinder and acting forces on the boom, picture from product brochure.

$$
\sum M_{o}=0 \Rightarrow F_{p}=\frac{F_{\text {load }} r \cos \left(\theta_{2}\right)}{r_{1} \sin \left(\theta_{1}-\theta_{2}\right)}
$$

The lift cylinder pressure $P_{c y l}$ can then be calculated as:

$$
P_{c y l}=\frac{F_{p}}{A_{\text {piston }}}
$$

where $F_{p}$ is the force exerted on the lift cylinder(s).

\subsection{Torque converter}

The speed ratio between output and input shafts speed of the TC is defined as:

$$
\phi=\frac{\mid \text { gearbox speed } \mid}{\omega_{i c e}}
$$

TC is modeled according to Guzzella and Sciarretta (2007) and its output torque is calculated using the TC characteristic curves, $\xi$ and $\psi$. The middle plot in Fig. 4 shows the normalized values for $\xi$. When $\phi>1$ power is transferred in reverse direction from gearbox side to engine side. Assuming the TC is $50 \%$ less efficient in the reverse direction, $\xi$ and $\psi$ are calculated for $\phi>1$. As seen in Fig. 4, direct use of $\psi$ in the TC model will produce discontinuities at $\phi=1$ which should be avoided. As a remedy, variable $\kappa$ is introduced and the torque on the gearbox side of TC is calculated as follows:

$$
\begin{aligned}
& T_{e, 1}=\xi(\phi)\left(\frac{\omega_{\text {ice }}}{1000}\right)^{2} \\
& T_{g b}=\kappa(\phi)\left(\frac{\omega_{\text {ice }}}{1000}\right)^{2}|\operatorname{sign}(\gamma)|, \kappa(\phi)=\psi(\phi) \xi(\phi)
\end{aligned}
$$

where $\gamma$ is the gear ratio in the gearbox and curve fitted functions represent $\kappa$ and $\xi$ values in the model. In order to study the effects of TC stiffness on the system, $\kappa$ and $\xi$ values for a TC with $15 \%$ lower torque output are also generated (TC 2). The power required for traction is then calculated as:

$$
P_{\text {trac }}=T_{e, 1} \omega_{\text {ice }}
$$

\subsection{Gearbox and wheels}

Aerodynamic losses are neglected due to low vehicle speeds and only rolling resistant forces are considered. The inertial forces induced by the rotating components in the powertrain are taken into account by adding the equivalent mass of the four rotating wheels into the vehicle mass.
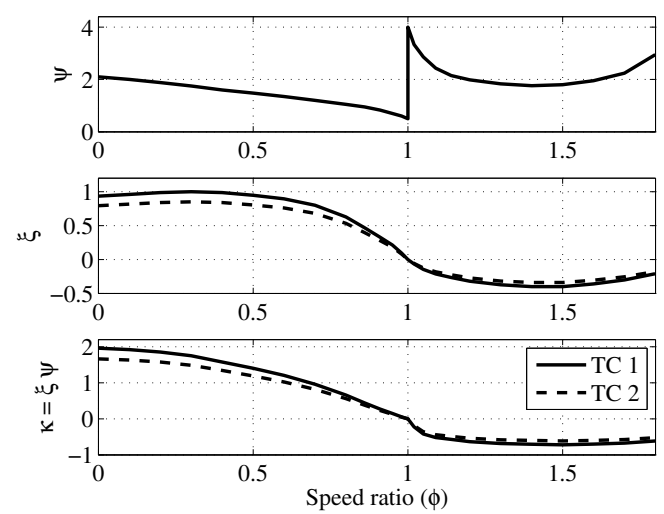

Fig. 4. TC characteristic curves, TC 2 is weaker and transfers $15 \%$ less torque on both directions.

$$
\begin{aligned}
& F_{\text {roll }}=c_{r}\left(M_{v e h}+M_{b u c}\right) g \\
& F_{\text {trac }}=\frac{T_{w}-\operatorname{sign}(V) T_{b}}{r_{w}} \\
& T_{w}=T_{g b} \eta_{g b} \gamma, \quad T_{b}=U_{b} \\
& M_{t o t}=M_{v e h}+M_{b u c}+\frac{4 J_{w}}{r_{w}^{2}}
\end{aligned}
$$

where $J_{w}$ and $r_{w}$ are the wheel inertia and radius, vehicle mass is $M_{v e h}=32$ [ton], $c_{r}=0.03$ is the rolling resistance coefficient and it is assumed that $\eta_{g b}=0.9$ is the gearbox efficiency. Using (25) - (28) the vehicle speed, $V$, and position, $S$, in (2) and (3) are determined.

\section{PROBLEM FORMULATION}

The wheel loader model described in section 2 is developed in MATLAB 7.13 (2011b), and the problem of finding the fuel optimal and time optimal system transients is then formulated and solved using PROPT (TOMLAB (2012)). The lift-transport section of the short loading cycle is divided into four phases with constant gearbox ratio in each. Table 1 shows the general structure of the multi-phase optimal control problem and the boundary conditions. Accordingly, the total fuel consumption during the lift-transport section is calculated as:

$$
M_{f}=\int_{0}^{t_{1}} \dot{m}_{f}+\int_{t_{1}}^{t_{2}} \dot{m}_{f}+\int_{t_{2}}^{t_{3}} \dot{m}_{f}+\int_{t_{3}}^{T} \dot{m}_{f}
$$

and minimum fuel and minimum time system transients are calculated by solving the following optimal control problems:

$$
\begin{array}{r}
\min M_{f} \text { or } \min T \\
\text { s.t. } \dot{x}=f(x, u)
\end{array}
$$

where $x$ is the system state and $\dot{x}$ is determined by (1) - (5). The distance to/from the reversing point is approximately 1.5 times the circumference of a wheel $(6.6[\mathrm{~m}])$, and the problem is solved for the same traveling distance in the reversing and forwarding sections. The zero value of the state derivatives at $\mathrm{t}=\mathrm{T}$ ensures stationary operating conditions at the end of the cycle. Since the problem is solved in four phases the continuity of the states between every two successive phase is ensured by applying the following constraints in PROPT:

$$
\begin{gathered}
x_{i, t_{j+1}(\text { start })}=x_{i, t_{j}(\text { end })} \\
i \in\{1,2,3,4,5\} \text { and } j \in\{1,2,3\}
\end{gathered}
$$


Table 1. Constraints in the optimal control problem formulation $\left(t_{s}\right.$ and $t_{e}$ denote the start and end times of each phase).

\begin{tabular}{|c|c|c|c|c|c|c|c|c|}
\hline & \multicolumn{2}{|c|}{$\begin{array}{c}\text { Phase 1 } \\
\text { Reversing } \\
\gamma=-60\end{array}$} & \multicolumn{2}{|c|}{$\begin{array}{c}\text { Phase } 2 \\
\text { Reversing } \\
\gamma=0\end{array}$} & \multicolumn{2}{|c|}{$\begin{array}{c}\text { Phase } 3 \\
\text { Forwarding } \\
\gamma=60\end{array}$} & \multicolumn{2}{|c|}{$\begin{array}{c}\text { Phase } 4 \\
\text { Forwarding } \\
\gamma=0\end{array}$} \\
\hline & $t_{s}=0$ & $t_{e}=t_{1}$ & $t_{s}=t_{1}$ & $t_{e}=t_{2}$ & $t_{s}=t_{2}$ & $t_{e}=t_{3}$ & $t_{s}=t_{3}$ & $t_{e}=T$ \\
\hline$\omega_{i c e}$ & 57 [rps] & - & & - & $1-$ & - & - & - \\
\hline$S$ & 0 & - & - & $-6.6[\mathrm{~m}]$ & । $-6.6[\mathrm{~m}]$ & - & - & 0 \\
\hline$V_{b u c}$ & 0 & - & - & - & $1-$ & - & - & 0 \\
\hline$H_{b u c}$ & $0.7[\mathrm{~m}]$ & - & - & - & 1 - & - & - & $5[\mathrm{~m}]$ \\
\hline V & 0 & - & - & 0 & 0 & & - & 0 \\
\hline$\dot{x}$ & - & - & - & - & :- & - & - & 0 \\
\hline
\end{tabular}

The system transients are also subjected to path and box constraints arising from the components limitations as follows:

$$
\begin{aligned}
& P_{c y l} \leq P_{c y l, \text { max }}, \quad V_{\text {buc }} \leq V_{\text {lift,max }}, \quad|V| \leq V_{\text {max }} \\
& \omega_{\text {ice,min }} \leq \omega_{\text {ice }} \leq \omega_{\text {ice,max }} \quad, \quad T_{\text {ice }} \leq T_{\text {ice,max }}\left(\omega_{\text {ice }}\right)
\end{aligned}
$$

Solving (30) with PROPT results in oscillatory optimal control trajectories as depicted in Fig. 5. The cause can be that the lifting system is modeled with a constant static efficiency resulting in a flat objective function near the optimal solution which is insensitive to the oscillations. The control oscillations are removed by including penalty terms for oscillations into the cost function formulation as follows:

$$
\begin{gathered}
\min \left(M_{f}+k_{1} \int_{0}^{T} U_{a b}^{2}+k_{2} \int_{0}^{T} U_{m f}^{2}\right) \\
\min \left(T+k_{1} \int_{0}^{T} U_{a b}^{2}+k_{2} \int_{0}^{T} U_{m f}^{2}\right) \\
\text { s.t. } \dot{x}=f(x, u)
\end{gathered}
$$

The problem is iteratively solved by decreasing the constants $k_{1}$ and $k_{2}$ until the penalty terms become zero. Using this technique, the system transients remain almost unchanged while the oscillations get attenuated and the optimal criterion function value changes less than $+1 \%$.

\section{RESULTS}

\subsection{Fuel optimal and time optimal transients}

Fig. 6 shows fuel and time optimal transients of the optimal control problem in (34) and (35) where all constraints in (32) and (33) are included. The minimum required time to complete the lift-transport section is $7.18 \mathrm{sec}$ consuming 0.119 Liter fuel, and in the fuel optimal operation, 0.055 Liter fuel is consumed and the cycle time is 27.99 sec. Engine operating points during these transients are illustrated in Fig. 7. In the time optimal case, the engine is mostly operated on the maximum torque limit while in the fuel optimal case the torque limit is never active and the engine is operated at low speed and torque regions. In reversing and forwarding sections of minimum time solutions, first the vehicle is accelerated up to highest cycle speeds while the bucket is not lifted. Then, the bucket lifting starts and continues at maximum possible speed while engine speed is slightly reduced to enable larger engine output torques such that half of the target end height is reached at the reversing point. At $t=0$ and $t=t_{2}$ the vehicle starts moving from stand still but fuel injection is lower at $t=t_{2}$. This is because at $t=0$ the
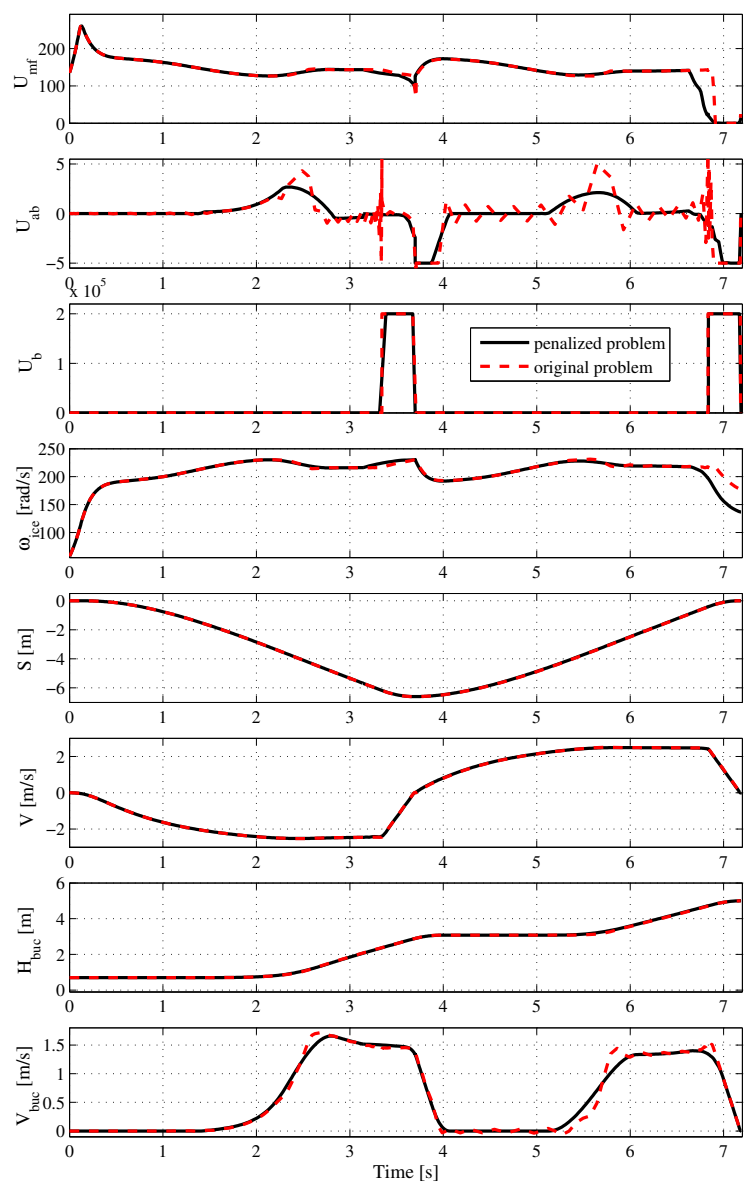

Fig. 5. Adding penalties terms for control oscillations slightly changes the engine speed trajectory while removes the oscillations in controls.

engine has started from idling speed and larger amounts of fuel are required to rev up the engine into high speeds while at $t=t_{2}$ it already operates at the maximum speed and less fuel is required.

In phases two and four the gearbox is in neutral and fuel is only consumed for engine acceleration and lifting. Higher engine speeds at $t=t_{2}$ correspond to higher available torques at the input to the TC enabling higher vehicle accelerations in forwarding phase and shorter cycle times which is the reason for controlling the engine into higher speeds at the end of phase two. However, lower engine speeds are selected in phase four since the power is required only for lifting and high torques are no more desirable at the TC input. Applying the penalties as described in section 3 , the lower levels of fuel injection are selected in phase four and kinetic energy of the engine is used for lifting. This is the reason for negative engine torques seen in Fig. 7 and also explains the lower engine speeds of the penalized problem in phase four as illustrated in Fig. 5.

The lower plot in Fig. 8 shows the power consumption at every instance of the time optimal cycle. It is seen that approximately the same amounts of energy is consumed for lifting and traction while $\mathrm{TC}$ is the major source of losses in the system. At $t=t_{2}$, high torque and speeds are available at the input to the TC while low powers are used on the gearbox side since the vehicle has just started to move and the gearbox speed is low which leads to large 

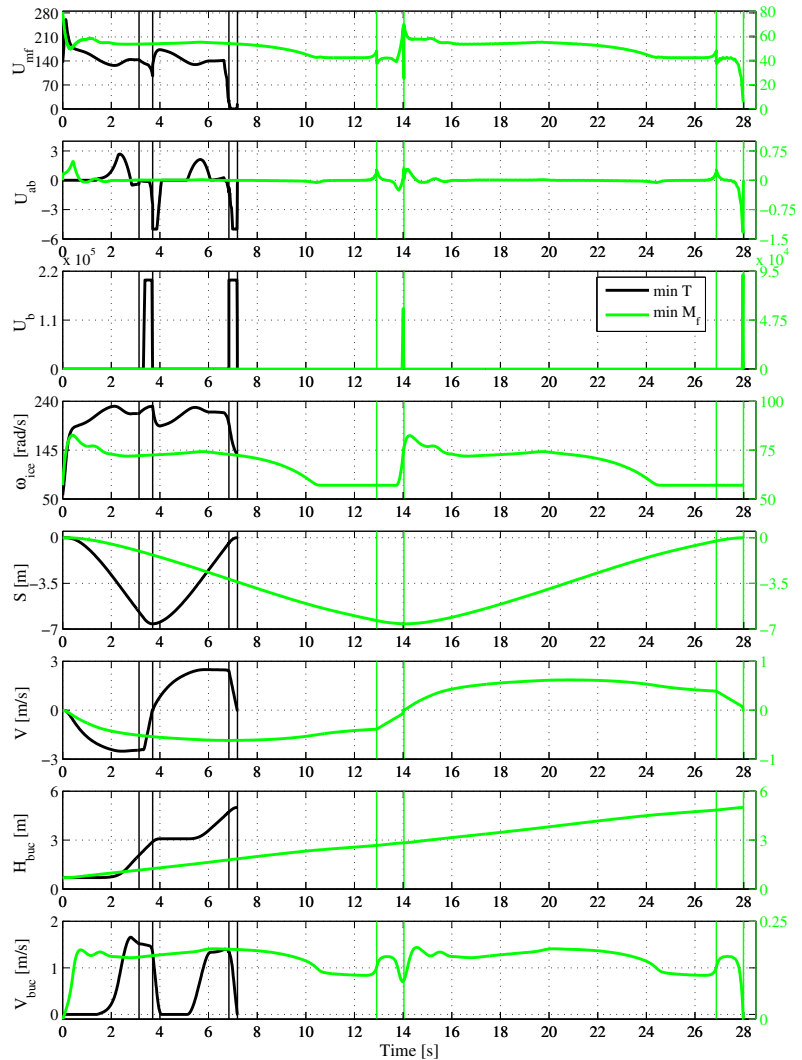

Fig. 6. Time optimal and fuel optimal state and control trajectories, vertical lines are phase boundaries.

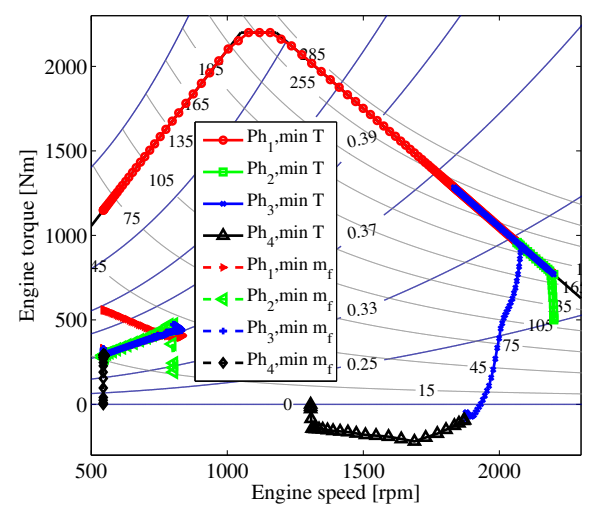

Fig. 7. Engine operating points in fuel optimal and time optimal transients (constant efficiency curves in blue and constant power $[\mathrm{kW}]$ curves in gray).

TC losses at $t=t_{3}$. The upper plot in Fig. 8 shows that except very short intervals at the beginning of phase one, the acceleration and lifting are performed simultaneously during the fuel optimal cycle. Compared to the time optimal transients, much less energy is allocated to engine acceleration and TC losses are lower. Fig. 9 shows speed ratio and efficiency of the TC during fuel optimal and time optimal transients where the efficiency is calculated as described in Guzzella and Sciarretta (2007). In the fuel optimal transients power is transferred from the engine side to the gearbox side of the TC in all times $(\phi<1)$ and the engine is controlled such that the TC achieves higher efficiencies minimizing the fuel consumption. In the time optimal case, the power transfer is reversed in a short

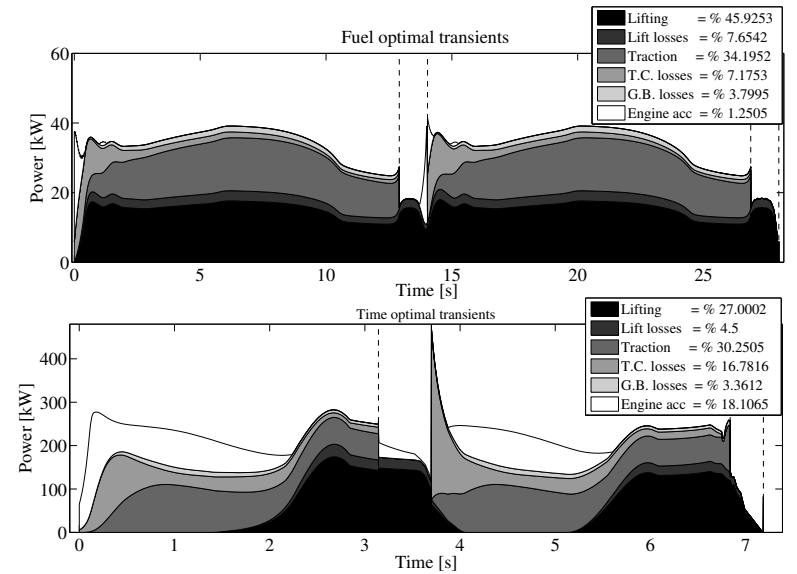

Fig. 8. Energy usage and losses in various components during the time optimal and fuel optimal transients, vertical lines are phase boundaries.
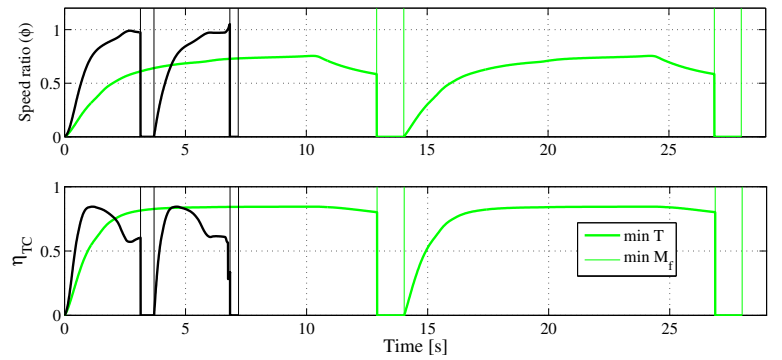

Fig. 9. Speed ratio in the TC during time optimal and fuel optimal transients, vertical lines are phase boundaries.

interval at the end of phase three meaning that the kinetic energy on the gearbox side is used in lifting.

\subsection{System sensitivity to $V_{b u c, \max }$ and $P_{c y l, \max }$ limits}

Among the path constraints presented in (32) and (33), $V_{\max }$ is never active and $\omega_{i c e, \min }, \omega_{i c e, \max }$ and $T_{i c e, \max }$ are imposed by the vehicle properties in product brochure. However, the limits for the $V_{\text {lift, } \max }$ and $P_{c y l, \max }$ are modeled based on the wheel loader geometry. Fig. 10 shows the time optimal state variables, the control inputs and the lift cylinder pressure where combinations of path constraints on $V_{b u c}$ and $P_{c y l}$ are included in the optimal control problem formulation. It is seen that $P_{c y l, \max }$ is the constraint with the lowest effects on the system transients. It only limits $U_{a b}$ in the first phase such that rapid bucket accelerations are avoided which is seen in blue and black colored $U_{a b}$ trajectories in Fig. 10. When the $V_{\text {lift, max }}$ constraint is included, the bucket acceleration starts earlier and engine speed remains higher during phases $2 \& 4$ since low engine speeds will result in low lifting speeds as described in section 2.2. This interval of higher engine speed increases fuel consumption and cycle time around $2 \%$.

\subsection{Trade-off between time and fuel optimal transients}

A Pareto front is calculated for both TC 1 and TC 2 described in section 2.3 by solving the following optimal control problem subjected to all constraints mentioned in section 3: 

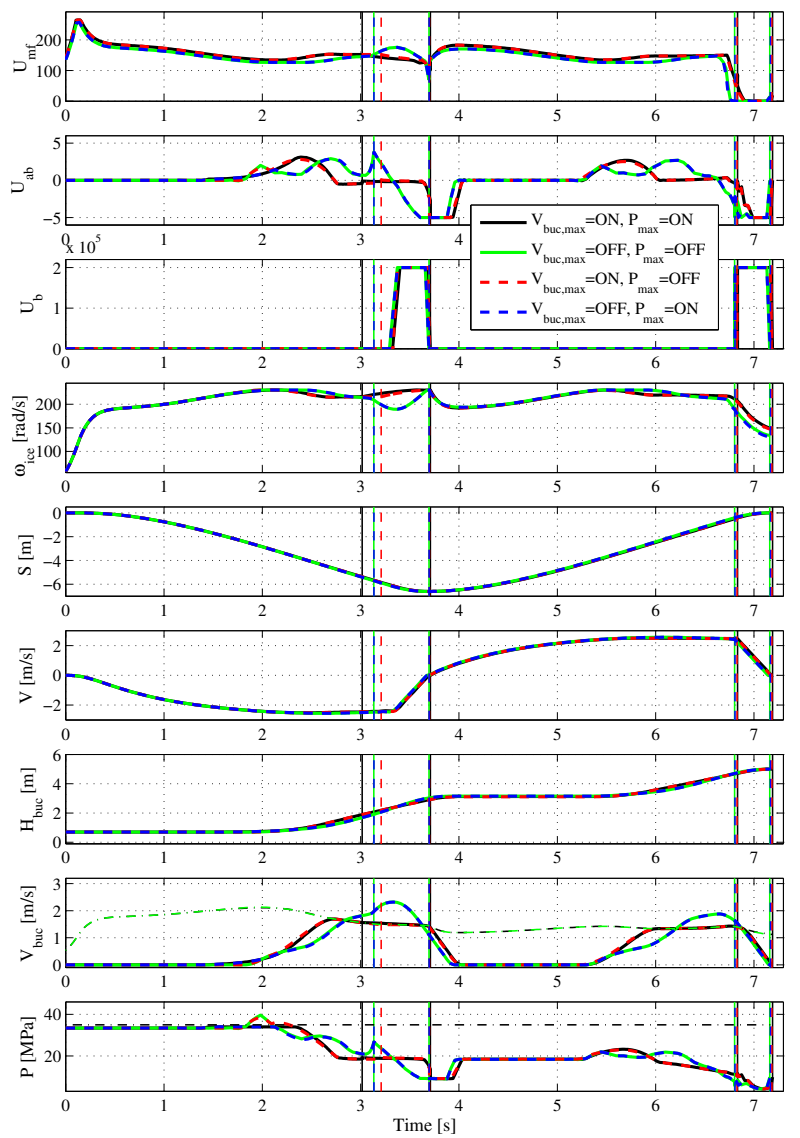

Fig. 10. Variations in time optimal transients arising due to lifting constraints, vertical lines are phase boundaries.

$$
\begin{gathered}
\min \left(\left(W_{1} \frac{M_{f}}{N_{1}}+W_{2} \frac{T}{N_{2}}\right)+k_{1} \int_{0}^{T} U_{a b}^{2}+k_{2} \int_{0}^{T} U_{m f}^{2}\right) \\
\text { s.t. } \dot{x}=f(x, u) \& W_{1}+W_{2}=1
\end{gathered}
$$

where $W_{1}$ and $W_{2}$ are changed so that the Pareto points are obtained while $N_{1}$ and $N_{2}$ are used to normalize fuel and time terms in the cost function. Fig. 11 illustrates the trade-off where all values are normalized by the maximum time and maximum fuel consumption of TC 2. The weaker TC has around $1.5 \%$ longer cycle times in the time optimal case and results in approximately $3 \%$ increase in the fuel consumption. The interesting result of the Pareto front is that duration of the fuel optimal cycle can be shortened by up to $50 \%$ while the fuel consumption only increases by $5 \%$. On the other hand, only $5 \%$ increase in the duration of time optimal cycle would reduce the fuel consumption by $30 \%$. This is in agreement with the results presented in Frank et al. (2012) where the trade-off is obtained through experiments.

\section{CONCLUSION}

A wheel loader is modeled as a system with five states and three control inputs. Discontinuities in the torque converter characteristics are avoided by introducing a new variable and it is assumed that the torque converter can also transfer power to the engine side when gearbox rotates faster than the engine. A multi-phase optimal control problem is formulated and solved to obtain minimum fuel and minimum cycle time transient in the lift-transport

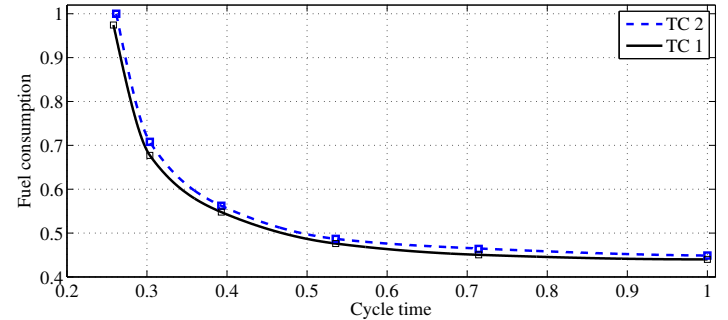

Fig. 11. Trade-off between cycle time and fuel consumption moving from time optimal towards fuel optimal transients.

section of the short loading cycle. It is shown that the engine mostly operates on the maximum torque limit in the time optimal transients and kinetic energy of engine is used for lifting when gearbox is in neutral near the end of the cycle. The power consumption and losses in different components are calculated and it is seen that the torque converter is the major cause of power losses during time optimal transients. In the fuel optimal case, the system is controlled such that the torque converter operates at higher efficiencies. The effect of including lift system limitations in the optimal control problem is studied and it is found that applying these limitation, the engine speed remains higher in the gearbox neutral phases of the cycle in order to produce larger powers for lifting. Finally, the trade-off between fuel consumption and cycle time is calculated for weak and stiff torque converters showing that the system with the weaker torque converter has higher fuel consumptions at all points of the Pareto front. The gain in the cycle time reduction is calculated to be larger than the loss in the fuel consumption increase when the cycle operation time is shortened to $50 \%$ of the fuel optimal operating cycles. Also, considerable fuel saving is viable by a slight increase in the duration of the time optimal cycles.

\section{REFERENCES}

Cobo, M., Ingram, R., and Cetinkunt, S. (1998). Modeling, identification, and real-time control of bucket hydraulic system for a wheel type loader earth moving equipment. Mechatronics, 8(8), $863-885$.

Eriksson, L. (2007). Modeling and control of turbocharged SI and DI engines. Oil \& Gas Sicence and Technology Rev. IFP, 523-538.

Filla, R. (2011). Quantifying Operability of Working Machines. Ph.D. thesis, Linköping University, Dissertation, NO. 1390.

Frank, B., Skogh, L., Filla, R., and Fröberg, A. (2012). On increasing fuel efficiency by operator assistant systems in a wheel loader. VTI 2012, 35-47.

Guzzella, L. and Sciarretta, A. (eds.) (2007). Vehicle Propulsion Systems, Introduction to Modeling and Optimization. Springer.

MATLAB 7.13 (2011b). "http: //www . mathworks. com/".

TOMLAB (2012). PROPT - Matlab Optimal Control Software, "http://www. tomdyn. com/".

Volvo (2012). L220G wheel loader product brochure, "http://www.volvoce.com/constructionequipment/ na/en-us/products/wheelloaders/wheelloaders/ L220G/Pages/specifications . aspx". 